Res Publica. Revista de Historia de las Ideas Políticas ISSN: $1576-4184$

\title{
El populismo como espejo del neoliberalismo
}

\section{A propósito de José Luis Villacañas, Populismo, Madrid, La Huerta Grande, 2015, 131 pp.}

César Ruiz Sanjuán*

El análisis del populismo que presenta José Luis Villacañas está dirigido a poner manifiesto la génesis de este fenómeno político en las condiciones estructurales de la sociedad moderna y la relación de continuidad que tiene con el neoliberalismo. $\mathrm{Su}$ tesis central es que el populismo es "una respuesta a la propias dimensiones problemáticas que la modernidad encierra y a la crisis social que inevitablemente genera bajo su forma presente de globalización neoliberal" (38). Desde esta perspectiva, el populismo aparece como el reflejo especular a nivel político del sistema económico y social instaurado por el neoliberalismo, de modo que cuanto más se imponga la forma de subjetividad que produce la sociedad neoliberal y mayor sea la desestructuración social que genera, más posibilidades tiene de expandirse el fenómeno populista.

Para desarrollar su planteamiento, Villacañas se confronta con las interpretaciones dominantes del populismo. En primer lugar, con aquella que lo considera como un tipo de lógica política que se impone fundamentalmente en países económica y políticamente atrasados, en los que la modernización no se ha realizado de manera exitosa y presentan déficits importantes en su construcción liberal. Esta forma de interpretación, cuya representante clásica es Margaret Canovan, ha encontrado una versión renovada en un reciente libro de Loris Zanatta ${ }^{1}$, con el que se confronta Villacañas de manera pormenorizada en los primeros capítulos del libro a fin de desmontar las tesis fundamentales del autor, y en oposición a ellas presentar su interpretación del populismo.

Al hilo de la discusión con la argumentación de Zanatta van saliendo a la luz los elementos constitutivos del populismo tal y como lo entiende Villacañas. Especial interés le concede en este sentido la distinción entre pueblo y nación, que en la interpretación de Zanatta se encuentran indiferenciados (24-27) 2 . Su objetivo es mostrar que a diferencia de la nación, el pueblo del populismo no existe como un hecho ya

Universidad Complutense de Madrid

ceruizsa@filos.ucm.es

$1 \quad$ L. Zanatta, El populismo, Buenos Aires, Katz, 2014.

2 Esta cuestión fundamental de la diferenciación entre nación y pueblo es abordada por Villacañas con un tratamiento aparte en el capítulo posterior "Institución, nación, pueblo" (55-63), en el que se analiza la relación que guardan ambas configuraciones políticas con el sistema institucional y las posibilidades de emergencia que en función de ello tiene el populismo. 
constituido, sino que es preciso construirlo. Se trata de un proceso de construcción hegemónica para el que resulta necesario que exista una instancia antagónica que sea determinada como el enemigo, en oposición al cual se configura el pueblo, siendo esta división dicotómica del campo social lo decisivo para que pueda surgir el fenómeno populista. Como conclusión de la confrontación con las insuficiencias de la interpretación de Zanatta se presenta la definición programática del concepto de "pueblo", cuyos términos fundamentales serán objeto de desarrollo en los siguientes capítulos del libro: "El pueblo es una comunidad construida mediante una operación hegemónica basada en el conflicto, que diferencia en el seno de una comunidad nacional o estatal entre amigos/enemigos como salida a la anomia política y fundación de un nuevo orden" (28).

Frente a la interpretación de Zanatta, que asocia el populismo con el retraso social y político propio de sociedades insuficientemente secularizadas en las que no se ha consumado la modernidad ${ }^{3}$, Villacañas sostiene que el populismo es un "acontecimiento interno de la modernidad" (32). Se trata de un intento de solución a los problemas estructurales derivados de la sociedad moderna como consecuencia de su forma de desarrollo económico y su configuración liberal ${ }^{4}$. En última instancia, la limitación de la interpretación de Zanatta estriba en su concepción de la modernidad como un proceso continuo de desarrollo progresivo, lo que le lleva a obviar las crisis consustanciales a dicho desarrollo. Entendiendo la modernidad, por el contrario, como un proceso que se impone precisamente a través de la crisis, Villacañas pone de manifiesto que el populismo es más bien un resultado de la desestructuración social que produce la modernidad (37).

En la perspectiva adoptada en esta forma de interpretación, Villacañas está de acuerdo con la teoría del populismo de Laclau, que lo considera un fenómeno específicamente moderno propio de la sociedad de masas. Se sorprende Villacañas, con razón, de que el libro de Zanatta no mencione siquiera la obra de Laclau La razón populista, donde se encuentra contenida la que puede ser considerada como la teorización más potente del populismo que existe en la actualidad ${ }^{5}$. De ella se ocupa ampliamente la exposición de Villacañas, a cuya discusión dedica gran parte de los capítulos centrales del libro, en los que va desgranando los elementos fundamentales de la teoría de Laclau al tiempo que se va confrontado críticamente con ellos. El carácter en buena medida divulgativo que pretende tener el libro de Villacañas hace que las referencias explícitas a la obra de Laclau se encuentren reducidas al mínimo necesario para desarrollar su argumentación, pero la teorización de Laclau del po-

Su tesis central es que "el populismo y su visión del mundo son enconados adversarios de la idea ilustrada de la modernidad" (L. Zanatta, Populismo, op. cit., p. 11), por lo que el ámbito propio de aparición del populismo serían sociedades que se encuentran en una "situación periférica respecto a los procesos que han abierto la vía a la modernidad occidental, desde la Reforma hasta la Ilustración, desde la revolución industrial hasta la constitucional" (ibidem, p. 14). Desde la comprensión de Zanatta, el populismo sería una reacción frente al progreso y a la modernización en defensa de tradiciones comunitarias y valores ancestrales.

$4 \quad$ Es preciso reconocer que Zanatta también refiere el fenómeno populista a países política y económicamente desarrollados en distintos pasajes de su libro. En cualquier caso, dichos pasajes entran en contradicción con su tesis central, y Zanatta no ofrece en ningún momento una argumentación coherente que permita resolver dicha contradicción.

5 Esta omisión no es exclusiva del libro de Zanatta, sino que se presenta en la mayor parte de las interpretaciones que abordan el fenómeno del populismo desde una perspectiva fundamentalmente historiográfica, las cuales por lo general son ajenas a formas de interpretación que adoptan una perspectiva más sociológica y filosófica, como es el caso de Laclau. 
pulismo es el verdadero referente polémico del libro. A lo largo del presente trabajo iremos poniendo de manifiesto estas referencias con el fin de contrastar la pertinencia del hilo conductor de la exposición de Villacañas, así como la fundamentación de su tesis central, que emerge como resultado de dicha confrontación. La conclusión de la misma, que queda enunciada con claridad en los capítulos finales del libro, muestra la distinta valoración política del populismo que se presenta en ambos casos. Mientras Laclau sostiene que el populismo es la respuesta política que permite construir el pueblo en la situación de ausencia de vínculos sustanciales propia de las democracias liberales, generando con ello un nuevo orden comunitario y profundizando el proceso de democratización social, Villacañas considera que el populismo más bien se limita a llenar el vacío político con una retórica que mantiene irresueltos los problemas generados en dichas formaciones sociales y exacerbados por la agenda neoliberal, pues precisamente esos problemas estructurales constituyen el suelo nutricio del populismo, por lo que tiene la necesidad ineludible de que permanezcan sin resolver aun en el caso de alcanzar el poder.

Como se ha puesto de manifiesto en las anteriores consideraciones, el punto de partida irrenunciable para el análisis del populismo lo constituye para Villacañas la moderna sociedad de masas (40). El fin del populismo es construir el pueblo, pero para ello solo cuenta con la masa heteróclita que es el fenómeno característico de las sociedades modernas, en las que las que las tradiciones ancestrales y los vínculos comunitarios se encuentran tendencialmente laminados. El populismo sabe que para poder construir la comunidad popular a partir de dichas condiciones es necesaria una política de masas. Aquí le concede Villacañas al populismo algo que muchos críticos le han negado: su carácter democrático. Considera que no se trata de una forma política de tendencias totalitarias, sino que aspira a llevar la democracia hasta el límite como vía para configurar al pueblo en el irrevocable contexto de la sociedad de masas $(42)^{6}$.

Villacañas subraya en este sentido el carácter posmarxista de la teorización del populismo de Laclau. Este considera que la masa que constituye la materia prima de la formación populista no se encuentra dividida en clases, por lo que la teoría marxista no resulta operativa para hacerse cargo de la heterogeneidad constitutiva de la realidad social contemporánea. Precisamente en el resto de esencialismo marxista que Laclau encuentra en Gramsci en relación a la función de las clases sociales se cifra su distancia respecto a él, cuyo concepto de hegemonía tan decisivo le resulta por lo demás para la elaboración de su propia teoría ${ }^{7}$. De lo que se trata para el populismo es de forjar una construcción hegemónica a partir de la que se pueda generar la homogeneidad que la configuración del pueblo requiere. Pero el punto de partida es necesariamente la irreductible heterogeneidad de la sociedad de masas, en la que no hay ninguna esencia subyacente ni ninguna instancia determinante, sino solamente proliferación de diferencias (44-45).

Estas diferencias son expresadas mediante demandas sociales, y el populismo hace de estas demandas la unidad básica del análisis social. Esto fue determinado

Sobre la comprensión de Laclau del populismo como una forma política intrínsecamente democrática, cf. $L a$ razón populista, Buenos Aires, Fondo de Cultura Económica, 2005, pp. 200-201, 258 ss.

E. Laclau, Ch. Mouffe, Hegemonía y estrategia socialista. Hacia una radicalización de la democracia, Madrid, Siglo XXI, 1987, p. 4, 82, 89. Cf. E. Laclau, “Construyendo la universalidad”, en: J. Butler, Judith, E. Laclau, S. Žižek, Contingencia, hegemonía, universalidad, Buenos Aires, Fondo de Cultura Económica, 2004, pp. 296298,305 . 
por Villacañas en un texto anterior como la "premisa liberal" del populismo ${ }^{8}$, y ahora incide nuevamente en esta tesis central $(16,49)$. Ello significa que el populismo parte de una teoría liberal de la sociedad, si bien su objetivo es subvertir la institucionalidad liberal a partir de una articulación de las demandas sociales en una cadena de equivalencia que las vincule entre sí en su oposición al poder. Dado que la heterogeneidad última que constituye lo social impide encontrar una demanda fundamental que incorpore a todas las otras demandas, de lo que se trata en este proceso es de construir un equivalente general que pueda representarlas a todas ellas.

Aquí es preciso preguntarse si Laclau mantiene con este planteamiento, tal y como pretende, la autonomía de la política de toda instancia social preexistente 9 . Que Laclau logre tal cosa es algo que Villacañas parece poner en duda, precisamente como consecuencia las bases liberales de la teoría del populismo. En este sentido, afirma que el populismo "quiere perseguir la lógica de la política como esfera propia de la acción social" (51). En el texto anteriormente citado sobre las raíces liberales del populismo, Villacañas ya había argumentado que la teoría de Laclau incurre en contradicciones insuperables, en tanto que partiendo de la diferenciación liberal entre sociedad civil y sociedad política, trata de convertir la pluralidad heterogénea de la sociedad civil en una oposición antagónica a partir de la que se constituye la esfera política ${ }^{10}$. Pero para ello se ve obligado a presuponer una fractura previa que divida el espacio social antagónicamente, pues si la diversidad de demandas sociales es atendida institucionalmente no se produce el antagonismo constitutivo del momento político que requiere el populismo para su emergencia ${ }^{11}$.

Toda la argumentación de Laclau a este respecto se cifra en la determinación de una lógica equivalencial, propia del populismo, que se presenta como opuesta a la lógica diferencial, propia de lo que denomina con un sentido peyorativo "administración" 12 , para distinguirla de la política como tal, que queda identificada para él con el populismo ${ }^{13}$. La exposición de Villacañas deshace la identificación de Laclau determinando como "nación" en términos de "formación de instituciones diferenciadas" o como "sociedad nacional bien construida institucionalmente" (55) lo que Laclau denomina como "administración", con lo que se impugna implícitamente su asimilación de lo político a la construcción del pueblo. La lógica de la diferencia consiste en atender a las demandas identificadamente a través de las instituciones

J. L. Villacañas, "The Liberal Roots of Populism. A Critique of Laclau", en: The New Centennial Review, Vol. 10, No. 2, Michigan State University Press, 2010, p. 166.

$9 \quad$ Esta es una insistencia constante en la obra de Laclau: "Si las fuerzas sociales constituyen el agrupamiento de una serie de elementos heterogéneos reunidos mediante la articulación política, es evidente que ésta es constitutiva y básica y no la expresión de algún movimiento más profundo subyacente" (La razón populista, op. cit., p. 184). "La política, en tanto que creación, reproducción y transformación de las relaciones sociales, no puede ser localizada a un nivel determinado de lo social, ya que el problema de lo político es el problema de la institución de lo social" (Hegemonía y estrategia socialista, op. cit., p. 252). Esta dimensión del pensamiento de Laclau ha sido expresada con claridad por Simon Critchley: "En su nivel más profundo, la categoría de hegemonía revela la lógica política de lo social, es decir, que la sociedad civil se construye políticamente mediante decisiones contingentes” (“¿Hay un déficit normativo en la teoría de la hegemonía?”, en: S. Critchley, O. Marchart (eds.), Laclau. Aproximaciones críticas a su obra, Fondo de Cultura Económica, Buenos Aires, 2008, p. 146).

10 J. L. Villacañas, "The Liberal Roots of Populism. A Critique of Laclau", op. cit., p. 162.

11 Ibidem, p. 164.

12 E. Laclau, La razón populista, op. cit., p. 33, 195, 279.

13 Ibidem, p. 192, 195. Cf. E. Laclau, "Populismo: ¿qué nos dice el nombre?", en: F. Panizza (ed.), El populismo como espejo de la democracia, Buenos Aires, Fondo de Cultura Económica, p. 69. 
adecuadas para ello, mientras el populismo se origina a partir de la vinculación de las demandas insatisfechas mediante una lógica de la equivalencia ${ }^{14}$. Esto significa que si las instituciones de la nación funcionan de manera adecuada y satisfacen las distintas demandas de manera particularizada, no se presentan las condiciones para que surja el fenómeno populista. Lo que implica que la construcción del pueblo requiere como condición de posibilidad de la existencia una situación de crisis, como resultado de la cual un funcionamiento insuficiente de las instituciones impida satisfacer un número creciente de demandas, que entonces pueden unirse entre sí en una cadena de equivalencia (59). Lo que sucede en este proceso es que las demandas dejan de constituir peticiones y se transforman en reclamos, que son una reivindicación activa a obtener lo que se demanda ante la ausencia de satisfacción, a partir de lo cual comienza la configuración del pueblo ${ }^{15}$. Para referirse a la situación de desestructuración política y social que el populismo requiere para emerger, Villacañas utiliza el término gramsciano de "crisis orgánica" $(57,60)$, al que refiere como análoga la expresión de Laclau de "anomia radical"16.

Villacañas señala el paralelismo de la concepción de Laclau con la distinción de Rancière entre la "política" y la "policía"17, así como con la distinción de Mouffe entre "lo político" y "la política" 18 . Con ello se pone de manifiesto que el populismo no opera a un nivel óntico, sino a un nivel ontológico, tal y como el mismo Laclau lo expresa en términos heideggerianos ${ }^{19}$. Villacañas traduce esta distinción a los términos de institucionalidad en los que se discute el planteamiento de Laclau en este capítulo del libro: "Esto significa que [el populismo] aspira no a intervenir en los órdenes institucionales concretos, sino a construir un nuevo fundamento del orden" (61). Los siguientes capítulos del libro se dirigen a mostrar cuál es ese fundamento, al hilo de lo cual tiene lugar la crítica de sus consecuencias políticas.

Estas consecuencias se derivan de la necesidad que tiene el populismo de fracturar el espacio social en un dualismo antagónico para generar un nuevo orden (67, 73). Es preciso producir la convicción de que el sistema institucional es inoperante

14 La razón populista, op. cit., pp. 104-105, 154. Cf. Hegemonía y estrategia socialista, op. cit., p. 150-151, 165.

15 Esta ambigüedad del término demanda y la transformación de las mismas de peticiones en reclamos como condición fundamental para la constitución del fenómeno populista ha sido abordado por Laclau en diversos lugares. Cf. La razón populista, op. cit., pp. 98-99. El populismo como espejo de la democracia, op. cit., pp. 54-55. Debates y combates. Por un nuevo horizonte de la política, Buenos Aires, Fondo de Cultura Económica, 2008, p. 25.

16 Laclau señala en a este respecto: "Cuando la gente se enfrenta a una situación de anomia radical, la necesidad de alguna clase de orden se vuelve más importante que el orden óntico que permita superarla" (La razón populista, op. cit., p. 116). Villacañas llama la atención sobre el hecho curioso de que haciendo Laclau un uso tan profuso del pensamiento de Gramsci, no se haya hecho cargo en profundidad de su concepto de "crisis orgánica" (82). Este concepto, en efecto, solo es mencionado tangencialmente por Laclau en dos ocasiones en La razón populista, cf. p. 166, 222. Una mayor incidencia tiene en Hegemonía y estrategia socialista, pero sin llegar a ocupar un lugar central.

17 Cf. J. Rancière, El desacuerdo. Política y filosofia, Buenos Aires, Nueva Visión, 1996, p. 35 ss. El mismo Laclau subraya los paralelismos de su interpretación con la de Rancière, al que afirma sentirse mucho más afín que a los otros autores con los que confronta su teoría como Žižek o Negri. Cf. La razón populista, op. cit., pp. 303-310.

18 Cf. Ch. Mouffe, En torno a lo político, Buenos Aires, Fondo de Cultura Económica, 2007, p. 15 ss. Una diferenciación que, según observa Oliver Marchart, si bien "se halla sólo implícitamente" en Laclau, "está presente en su obra", lo que explica "la importancia que ha cobrado en los teóricos relacionados con su trabajo" (O. Marchart, El pensamiento político posfundacional. La diferencia política en Nancy, Lefort, Badiou y Laclau, Buenos Aires, Fondo de Cultura Económica, 2009, p. 190).

19 La razón populista, op. cit., pp. 114-115. Cf. El populismo como espejo de la democracia, op. cit., p. 53. 
para satisfacer las demandas, y ello porque está administrado al servicio de una élite oligárquica que es ajena a las necesidades de la población. Esta fractura social permite que las demandas insatisfechas se unan entre sí, de modo que "el grupo de reclamantes excluye de sí a una parte del cuerpo social para tornarse ellos mismos totalidad", reuniendo "todas sus demandas en una sola: ser pueblo" $(68)^{20}$. Toda esta operación se basa en un lenguaje metafórico que apela de manera decisiva a los afectos, que tienen un papel fundamental en la construcción hegemónica del pueblo y en la forma de representación política que se deriva de ello. Pero mientras este proceso es resaltado afirmativamente por Laclau haciéndolo equivalente a la política tout court, el análisis de Villacañas se dirige a mostrar las funestas consecuencias que tiene esta fundación de un nuevo orden. Se pone así de manifiesto la distinta concepción de lo político que subyace al planteamiento de Villacañas frente al de Laclau.

Esta diferencia, que llevará a Villacañas a reivindicar el republicanismo como forma política frente al populismo, tiene como uno de sus elementos fundamentales la necesaria dimensión institucional que para él ha de tener lo político, la cual es anulada por el populismo, y ello por su propia necesidad interna: "El populismo siempre tiene que mantener una dimensión antiinstitucional, y jamás puede dar el paso la normalización de la política, a un «orden usual de las cosas»" $(82)^{21}$. Ciertamente la existencia de un sistema institucional ineficiente facilita la emergencia del populismo, pues a sus líderes les resulta más fácil mostrar la veracidad de su construcción retórica de un antagonista. Pero dado que el populismo necesita que las demandas se encuentren insatisfechas para que entren en una relación de equivalencia, en caso de alcanzar el poder no podrá generar un sistema institucional eficiente que satisfaga las demandas, pues ello produciría la disolución del pueblo. Lo que implica que el populismo, "en lugar de usar el poder para superar la crisis y recomponer la atención a las demandas parciales, usa el poder para perpetuar la crisis institucional, generando en la formación del pueblo el muro de contención del desorden que él mismo ayuda a mantener" (90). Ello lleva ineludiblemente a la inoperatividad del populismo como forma política, pues tiene que mantener necesariamente las condiciones a partir de las que ha surgido. A pesar su aparente carácter crítico contra el sistema, en realidad no producirá ningún cambio sustantivo cuando llegue al poder, lo que hace "que muchos líderes populistas en el poder, sigan comportándose como si estuvieran en la oposición" (74). Evidentemente, una vez que el populismo detenta el poder ejecutivo, la retórica populista consistirá en negar que dicha inoperatividad se deba a su ejercicio del poder, atribuyéndola a las élites económicas que siguen actuando en la sombra e impiden funcionar eficazmente a las instituciones (89). En definitiva, es esencial para el populismo mantener identificado al enemigo, pues la condición de posibilidad de que el pueblo se mantenga unido es la oposición frente a ese enemigo común. La diferencia amigo/ enemigo es necesaria, por tanto, no sólo para realizar la construcción hegemónica

20 Dicho en los términos a los recurre con frecuencia Laclau, "a fin de concebir el «pueblo» del populismo necesitamos una plebs que reclame ser el único populus legítimo - es decir, una parcialidad que quiera funcionar como la totalidad de la comunidad" (La razón populista, op. cit., p. 108). Cf. ibidem, p. 122, 149.

21 Sobre la necesidad de "desinstitucionalización" que requiere el populismo como forma política ha insistido Antonio Rivera, "De la hegemonía al populismo: Ernesto Laclau, la evolución de un «schmittiano antischmittiano»", en: R. Castro, (ed.), Poshegemonía. El final de un paradigma de la filosofía politica en América Latina, Madrid, Biblioteca Nueva, 2015, p. 43. 
que permita al populismo llegar al poder, sino que lo es también para que pueda mantenerse en el poder una vez alcanzado ${ }^{22}$.

Otra vertiente de consecuencias políticas del populismo a la que se dirigen las críticas fundamentales de Villacañas tiene que ver con la cuestión de la representación. La lógica de la equivalencia en la que se basa el fenómeno populista requiere de una instancia personal que represente todas las demandas, lo que establece la necesidad que tiene el populismo de un líder carismático (75). Su función es ciertamente esencial, pues articula la cadena equivalencial, pero su realidad es vacía, no es más que el punto nodal que unifica las demandas insatisfechas ${ }^{23}$. Ello significa que se limita a representarlas, pero no las satisface: "Eso haría del líder populista un constructor institucional, lo que llevaría a la disolución de la formación populista" (81). Villacañas pone de manifiesto a partir del análisis del líder populista que este en realidad no es más que un momento trascendente $e^{24}$, que realiza la unificación del grupo de manera puramente nominal, en tanto que es solo el nombre del líder lo que llena el vacío del significante ${ }^{25}$. Ello sitúa al populismo en la línea del nominalismo hobbesiano, con lo que "la modernidad política alcanza su plenitud" $(80)^{26}$. Se constata así que el populismo como forma política no es más que otro avatar del nominalismo que ha caracterizado a la política moderna desde sus inicios, con lo que se pone de manifiesto nuevamente su intrínseca relación con el liberalismo.

Ello lleva a Villacañas a confrontarse una vez más con la autocomprensión de Laclau sobre la relación del populismo con el liberalismo. Este considera que la tradición liberal y la democrática, si bien han caminado juntas durante un cierto periodo histórico, se encuentran actualmente separadas, pues la irrupción del neoliberalismo ha dado lugar a formas de gobernanza ajenas a toda legitimación democrática. Frente a este abandono de las formas democráticas que ha tenido lugar en el liberalismo como consecuencia de su desarrollo neoliberal, el populismo se presentaría como una reivindicación de la democracia popular (85-86). Pero la relación entre populismo y neoliberalismo va a aparecer más bien en la exposición de Villacañas como una simbiosis, y no como una oposición irreductible tal y como quiere mostrarla Laclau.

Para poner de manifiesto esta simbiosis, el análisis de Villacañas se centra en la esencial dimensión afectiva que conlleva el proceso de identificación con el líder populista. Aquí Laclau toma como referente a Freud, de cuya teoría sobre la psicología de las masas se sirve para analizar el papel central del afecto en el vínculo del pueblo con el líder, sosteniendo que el proceso que tiene aquí lugar se basa en un "investidura radical" 27 . Tras poner en tela de juicio la pertinencia del anclaje del populismo en

22 Villacañas subraya el papel esencial de la distinción schmittiana amigo/enemigo en el populismo, pero muestra asimismo las diferencias fundamentales que existen entre el modo en que funciona tal distinción en Carl Schmitt y cómo lo hace en el populismo (71-72).

23 La razón populista, op. cit., p. 95, 130, 214. Cf. Debates y combates, op. cit., p. 22 ss.

24 Acerca de la cuestión de la trascendencia ha incidido también la crítica de Jon Beasley-Murray, Poshegemonía. Teoría política y América Latina, Buenos Aires, Paidós, 2010, p. 70, 74.

25 Respecto a este proceso indica Laclau que "la lógica de la equivalencia conduce a la singularidad, y ésta a la identificación de la unidad del grupo con el nombre del líder" (La razón populista, op. cit., p. 130). En este aspecto del planteamiento de Laclau tiene especial relevancia su confrontación con Žižek, cf. J. Butler, Judith, E. Laclau, S. Žižek, Contingencia, hegemonía, universalidad, op. cit., p. 288 ss.

26 Una crítica más amplia de la dimensión nominalista del pensamiento de Laclau puede verse en el texto de Villacañas "The Liberal Roots of Populism. A Critique of Laclau", op. cit., pp. 171-172.

27 Como señala Laclau en relación a ello, "está claro que si una entidad se convierte en objeto de una investidura - 
la teoría freudiana, Villacañas muestra que la identificación es más plena cuanto más primaria es la subjetividad, pues en ese caso la formación psíquica de los individuos es de naturaleza predominantemente narcisista, lo que facilita que se identifiquen con el líder (99). Y como va a mostrar a continuación, la sociedad neoliberal fomenta el desarrollo de este tipo de subjetividad narcisista, lo que le sirve en bandeja al populismo su materia prima.

Bajo el título "Una alianza inesperada" (103-110) presenta Villacañas la confluencia que se produce entre neoliberalismo y populismo, que es donde desemboca todo el análisis crítico del libro. La sociedad neoliberal, al subordinar todas las instancias sociales a la lógica del mercado, produce seres humanos que sólo persiguen el consumo y la satisfacción de sus propios deseos, cuyos rasgos psicológicos característicos son el hedonismo y el narcisismo. Los hombres insertos en esta forma de sociedad quedan reducidos a una escala económica y regidos por una concepción individualista, quedando progresivamente suprimidos todos los vínculos afectivos. Y este es precisamente el tipo de personalidad que constituye el caldo de cultivo para el populismo, lo que lleva a Villacañas a una ineludible conclusión: "Cuanto más triunfe el neoliberalismo como régimen social, más probabilidades tiene el populismo como régimen político" (105). A ello hay que sumar las crisis sistémicas de una intensidad creciente a que da lugar periódicamente el neoliberalismo, con la progresiva pauperización que estas llevan consigo y la consiguiente apertura de la brecha social entre las élites privilegiadas y las masas excluidas de los beneficios sociales. Así como la privatización rampante de los servicios públicos que tiene lugar bajo la égida neoliberal, lo que debilita las instituciones en su capacidad de satisfacer demandas y hace que estas se conviertan en reivindicaciones. En estas condiciones, el discurso populista que señala a una casta hostil al pueblo como causante de la polarización social y acusa a las instituciones de inoperantes resulta cada vez más plausible.

Tras mostrar que es la sociedad neoliberal la que promueve la subjetividad en la que hace presa el fenómeno populista y genera sus condiciones de existencia, Villacañas va a presentar el republicanismo como la única forma política que puede servir de dique de contención: "El verdadero pensamiento alternativo tanto frente al nacionalismo propio de la democracia liberal identitaria como del nuevo pueblo soberano del populismo, es el republicanismo. Populismo es democracia (puede que incluso liberal) sin republicanismo" (109-110). El republicanismo cívico es a juicio de Villacañas el único sistema político en el que una ciudadanía madura puede hacer frente al carácter destructivo de la lógica neoliberal y a la laminación de todas las estructuras sociales que esta lleva consigo, a lo que el populismo no se enfrenta realmente, limitándose a desplazarlo a un ámbito metafórico a través de sus dispositivos retóricos: "En consecuencia, debemos decir que hay una gran solidaridad entre el neoliberalismo que destruye las bases mismas de un republicanismo socio-político centrado en instituciones públicas y el populismo que intenta una solución de urgencia" (116). El republicanismo es así la única forma política alternativa tanto al neoliberalismo como al populismo que puede fomentar un entramado institucional solvente, que favorezca políticas distributivas capaces de satisfacer las demandas sociales de la ciudadanía sobre la base de una comunidad activa que participe de manera efectiva en la vida política.

como estar enamorado u odiar -, la investidura pertenece necesariamente al orden del afecto" (La razón populista, op. cit., p. 142). Cf. ibidem, p. 148, 281. 